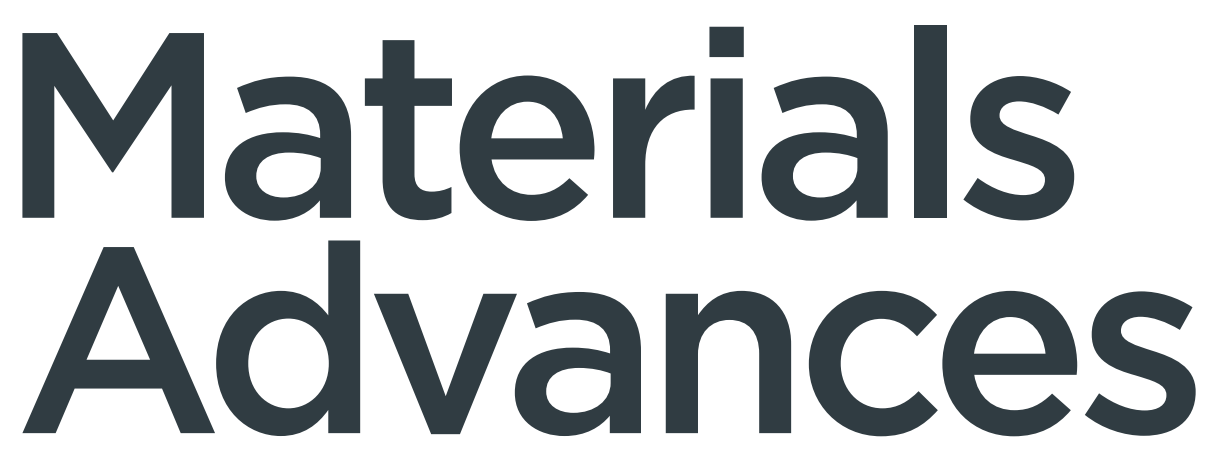

Number 9

December 2020

Pages 3075-3608

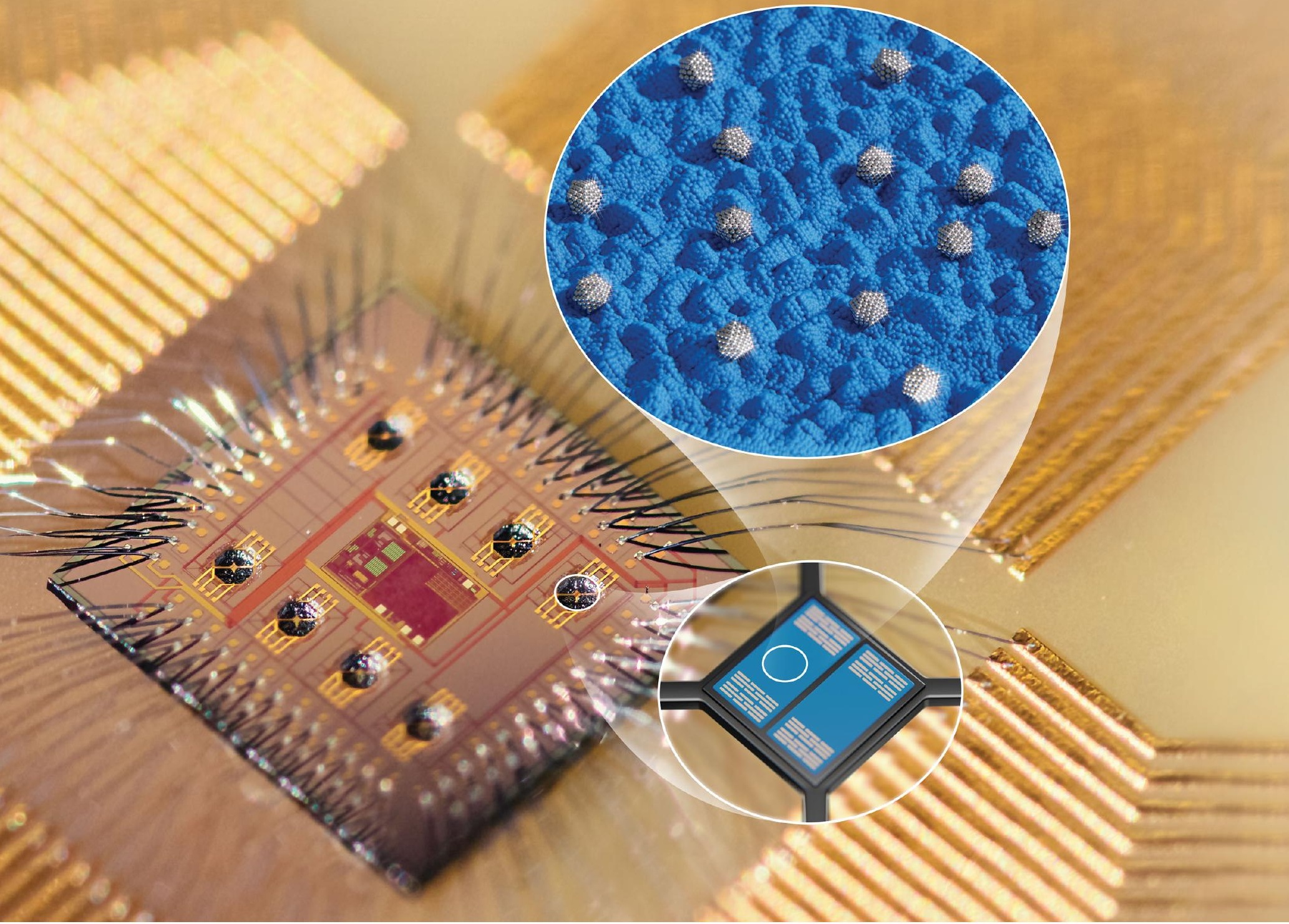

ISSN 2633-5409

\section{PAPER}

Stephan Steinhauer, Anton Köck et al.

Atomic-scale structure and chemical sensing application of ultrasmall size-selected Pt nanoparticles supported on $\mathrm{SnO}_{2}$ 


\section{A) Check for updates}

Cite this: Mater. Adv., 2020, 1,3200

Received 25th April 2020, Accepted 3rd October 2020 DOI: $10.1039 / \mathrm{d} 0 \mathrm{ma} 00244 \mathrm{e}$

rsc.li/materials-advances

\title{
Atomic-scale structure and chemical sensing application of ultrasmall size-selected Pt nanoparticles supported on $\mathrm{SnO}_{2}$
}

\author{
Stephan Steinhauer, (D) $\dagger^{\star^{a}}$ Eva Lackner, ${ }^{b}$ Florentyna Sosada-Ludwikowska, ${ }^{b}$ \\ Vidyadhar Singh, (D) $\ddagger^{\mathrm{a}}$ Johanna Krainer, ${ }^{\mathrm{b}}$ Robert Wimmer-Teubenbacher, ${ }^{\mathrm{b}}$ \\ Panagiotis Grammatikopoulos, (DD ${ }^{a}$ Anton Köck* ${ }^{\text {b }}$ and Mukhles Sowwan ${ }^{a}$
}

\begin{abstract}
The surface reactivity of metal oxide materials can be enhanced by nanoparticle decoration, which is of crucial importance in catalysis and chemical sensing applications. Here, we employ ultrasmall Pt nanoparticles for the functionalization of tin oxide $\left(\mathrm{SnO}_{2}\right)$ thin film-based chemoresistive sensors integrated in complementary metal-oxide-semiconductor technology. Size-selected Pt nanoparticles with an average diameter below $2 \mathrm{~nm}$ were fabricated by a solvent-free gas-phase synthesis approach and deposited onto the $\mathrm{SnO}_{2}$ sensing layer surfaces, which resulted in carbon monoxide sensing properties with minimized humidity interference. The atomic-scale structure of ultrasmall Pt nanoparticles supported on $\mathrm{SnO}_{2}$ was studied by in situ transmission electron microscopy, performing heating experiments in reactive gas atmosphere relevant for sensor operation. Our results reveal the formation of Pt oxide phases and nanoparticle-support interactions, which contributes to a more detailed understanding of the structure-property relationships in the $\mathrm{SnO}_{2}-\mathrm{Pt}$ nanomaterial system.
\end{abstract}

\section{Introduction}

Metal oxide nanomaterials have been extensively studied for the realization of high-performance, low-cost devices for chemical sensing of gas molecules, which is relevant in multiple application areas including environmental air quality monitoring as well as detection of toxic and explosive gases. Significant progress has been achieved in optimizing the sensor device properties by tailoring the nanostructure morphology and by multi-component nanomaterial approaches including surface modification and additive doping. ${ }^{1,2}$ Tin oxide $\left(\mathrm{SnO}_{2}\right)$, a wide band gap n-type semiconductor, is one of the most commonly used sensing materials. It is well established that the performance of $\mathrm{SnO}_{2}$-based devices can be enhanced by employing sensing elements based on heterostructures ${ }^{3-7}$ or by decorating the metal oxide with catalytic noble metal additives $^{8,9}$ including Pt nanoparticles. ${ }^{10-14}$ In a similar way, different $\mathrm{SnO}_{2}-\mathrm{Pt}$ nanomaterial configurations were employed

\footnotetext{
${ }^{a}$ Nanoparticles by Design Unit, Okinawa Institute of Science and Technology (OIST) Graduate University, 1919-1 Tancha, Onna-Son, Okinawa, 904-0495, Japan

${ }^{b}$ Materials Center Leoben Forschungs GmbH, Roseggerstrasse 12, 8700 Leoben, Austria.E-mail: anton.koeck@mcl.at

$\dagger$ Present address: Department of Applied Physics, KTH Royal Institute of Technology, 10691 Stockholm, Sweden. E-mail: ssteinh@kth.se

\# Present address: Department of Physics, Jai Prakash University, Chapra-841301, Bihar, India.
}

to promote chemical reactions in (electro-) catalysis. ${ }^{15-18}$ Previous reports correlating the chemoresistive response of Pt-doped $\mathrm{SnO}_{2}$ thick film devices with spectroscopy results ${ }^{19,20}$ provided crucial insights into the underlying mechanisms of gas-solid interactions. However, it is of vital importance to study the atomic-scale morphology of $\mathrm{SnO}_{2}-\mathrm{Pt}$ nanomaterials subjected to reactive gas atmospheres at elevated temperatures to obtain more detailed knowledge on the structure-property relationships in this material system.

In this article, we present gas-phase synthesis of ultrasmall Pt nanoparticles (average diameter $<2 \mathrm{~nm}$ ) for the surface decoration of nanocrystalline $\mathrm{SnO}_{2}$ thin films and $\mathrm{SnO}_{2}$ nanowires. Magnetron sputtering inert-gas condensation, a versatile technique for the growth of single- and multicomponent nanoparticles with controlled size and morphology, ${ }^{21-23}$ was employed for the deposition of pre-formed, size-selected Pt nanoparticles. A wide range of nanoparticle functionalities has been achieved with this method, e.g., percolating nanoparticle films for chemoresistive sensing, ${ }^{24-30}$ nanoparticle-decorated metal oxide nanowire devices for chemoresistive sensing, ${ }^{31-33}$ supported nanoparticles for catalysis and electrochemistry, ${ }^{34-37}$ magnetic nanoparticles, ${ }^{30,38-40}$ nanoparticles embedded in multi-layered anodes for lithium ion batteries ${ }^{41}$ and nanoportals for hydrogen storage applications. ${ }^{42}$ Here, we demonstrate a new approach for the surface functionalization of micro-machined chemical sensor devices realized in complementary metal-oxide-semiconductor 
(CMOS) technology, in particular by depositing ultrasmall Pt nanocatalysts by magnetron sputtering inert-gas condensation onto nanocrystalline $\mathrm{SnO}_{2}$ thin films integrated on a suspended microhotplate platform. We focus on studying the sensing performance for the toxic gas carbon monoxide (CO) in humid atmosphere, which is highly relevant for safety applications as well as environmental monitoring. Importantly, it was found that our CMOS-integrated $\mathrm{SnO}_{2}-\mathrm{Pt}$ nanomaterial system is ideally suited for CO sensing with minimized humidity interference. Furthermore, in situ transmission electron microscopy (TEM) experiments are presented, studying the thermal stability of ultrasmall Pt nanoparticles in a reactive gas atmosphere. Using single-crystalline $\mathrm{SnO}_{2}$ nanowire supports as model system, we investigate the atomic-scale structure of the nanocatalysts after heating in an oxygen environment. Our results show that nanoparticle-support interactions influence the nanoparticle morphology, leading to oxidized Pt clusters with elongated shapes and with crystal structures epitaxially aligned to the $\mathrm{SnO}_{2}$ support.

\section{Methods}

\subsection{Synthesis of $\mathrm{SnO}_{2}$ thin films and nanowires}

$\mathrm{SnO}_{2}$ thin films with a thickness of $50 \mathrm{~nm}$ were deposited by spray pyrolysis using tin chloride pentahydrate in ethyl acetate as precursor material. The samples were placed on a hotplate at a temperature of $400{ }^{\circ} \mathrm{C}$ and the solution was sprayed by an atomizing nozzle using $\mathrm{N}_{2}$ as carrier gas. ${ }^{43}$ Subsequent annealing was performed at $400{ }^{\circ} \mathrm{C}$ in ambient air to obtain nanocrystalline $\mathrm{SnO}_{2}$ structure. Deposition was performed on TEM support films (silicon nitride, thickness $15 \mathrm{~nm}$ ) for characterization and on CMOS chips with integrated microhotplate structures for chemoresistive sensing experiments (see Section 2.4). $\mathrm{SnO}_{2}$ nanowires were synthesized in a constant $\mathrm{Ar}$ gas flow $(1000 \mathrm{sccm})$ at $900{ }^{\circ} \mathrm{C}$ for $1 \mathrm{~h}$ using $\mathrm{SiO}_{2} / \mathrm{Si}$ substrates with a $\mathrm{Cu}$ catalyst as growth substrate and $\mathrm{SnO}_{2}$ thin films (thickness $500 \mathrm{~nm}$; spray pyrolysis deposition as described above) on a separate $\mathrm{SiO}_{2} / \mathrm{Si}$ sample as source material. ${ }^{43}$

\subsection{Deposition of size-selected Pt nanoparticles}

Pt nanoparticles were fabricated by magnetron sputtering inertgas condensation in a high-vacuum deposition system using a cluster beam source combined with an in-line quadrupole mass filter (QMF) for size selection. ${ }^{22}$ The base pressure of the instrument was $\sim 10^{-8}$ mbar. During nanoparticle synthesis, the main chamber pressure was $\sim 10^{-4}$ mbar and the aggregation zone pressure was $\sim 10^{-1}$ mbar. Size-selected Pt nanoparticles were directly deposited on carbon TEM support films, Si substrates (root mean square roughness $0.2 \mathrm{~nm}$ ) for atomic force microscopy (AFM) characterization (Bruker Multimode 8 in tapping mode), silicon nitride TEM support films covered with $\mathrm{SnO}_{2}$ thin films, membrane-based TEM heating chips with mechanically-transferred $\mathrm{SnO}_{2}$ nanowires and CMOSintegrated $\mathrm{SnO}_{2}$ thin film devices. The synthesis conditions were a magnetron power of $3 \mathrm{~W}$, a constant flow of $70 \mathrm{sccm} \mathrm{Ar}$ and $5 \mathrm{sccm} \mathrm{He}$, and an aggregation length of $80 \mathrm{~mm}$. The substrate holder was rotated at $2 \mathrm{rpm}$ to ensure homogeneous nanoparticle deposition.

\subsection{Transmission electron microscopy characterization and in situ heating experiments in oxygen atmosphere}

An FEI Titan Environmental TEM equipped with a spherical aberration corrector for the objective lens was used at an operation voltage of $300 \mathrm{kV}$ for imaging, diffraction and energy-dispersive X-ray spectroscopy. The $\mathrm{Pt}$ nanoparticle size distribution was obtained from low-magnification TEM micrographs by means of automated image analysis with the software ImageJ, measuring projected areas and assuming spherical geometries. In situ heating experiments of $\mathrm{SnO}_{2}$ thin films $/ \mathrm{SnO}_{2}$ nanowires decorated with $\mathrm{Pt}$ nanoparticles were performed at an oxygen pressure of $20 \mathrm{mbar}$ and a temperature of $350{ }^{\circ} \mathrm{C}$ for $30 \mathrm{~min}$. The thin films on silicon nitride TEM support films were heated with a furnace-type Gatan heating holder, whereas the nanowires were heated on membranebased heating chips using a Protochips Aduro holder.

\subsection{Device fabrication and chemoresistive sensing}

The CMOS integration of $\mathrm{SnO}_{2}$ thin film sensors was achieved by employing spray pyrolysis as back-end fabrication step. Photolithography followed by Ar ion etching was performed for patterning the $\mathrm{SnO}_{2}$ thin film. The CMOS chips were realized in standard $0.35 \mu \mathrm{m}$ technology (ams AG) and the microhotplate devices were under-etched by an isotropic $\mathrm{XeF}_{2}$ dry etching process to ensure thermal insulation from the rest of the substrate. ${ }^{44,45}$ The performance of CMOS-integrated sensors was evaluated in an automated measurement setup. Synthetic air at three relative humidity levels (humidification via water bubbler; relative humidity continuously measured with a commercial sensor) was employed as background gas. Pulses of CO at concentrations between $10 \mathrm{ppm}$ and $200 \mathrm{ppm}$ were introduced by adjusting the flow of background and target gas by mass flow controllers at corresponding ratios (constant total gas flow of $1000 \mathrm{sccm}$ ). The microhotplates were heated to the operation temperatures $350{ }^{\circ} \mathrm{C}, 375{ }^{\circ} \mathrm{C}$ and $400{ }^{\circ} \mathrm{C}$ by biasing an embedded polysilicon resistor and the $\mathrm{SnO}_{2}$ sensing layer resistance was measured via electrical contacts connected to underlying metallization layers and contact pads. The relative resistance changes due to the interaction with $\mathrm{CO}$, i.e., the sensor response $\mathrm{S}$, was evaluated according to $S=$ $\left(R_{\text {air }}-R_{\text {gas }}\right) / R_{\text {air }}$, where $R_{\text {gas }}$ is the resistance in test gas and $R_{\text {air }}$ is the resistance in background gas.

\section{Results and discussion}

Pt nanoparticles were synthesized by magnetron sputtering inert-gas condensation and their size distribution was adjusted by fine-tuning the deposition parameters, in particular the magnetron power, the gas flow and the QMF settings, resulting in size control in the range of $1 \mathrm{~nm}$ to $5 \mathrm{~nm}$. Here, we focus on ultrasmall Pt nanoparticles with average diameters below $2 \mathrm{~nm}$ 


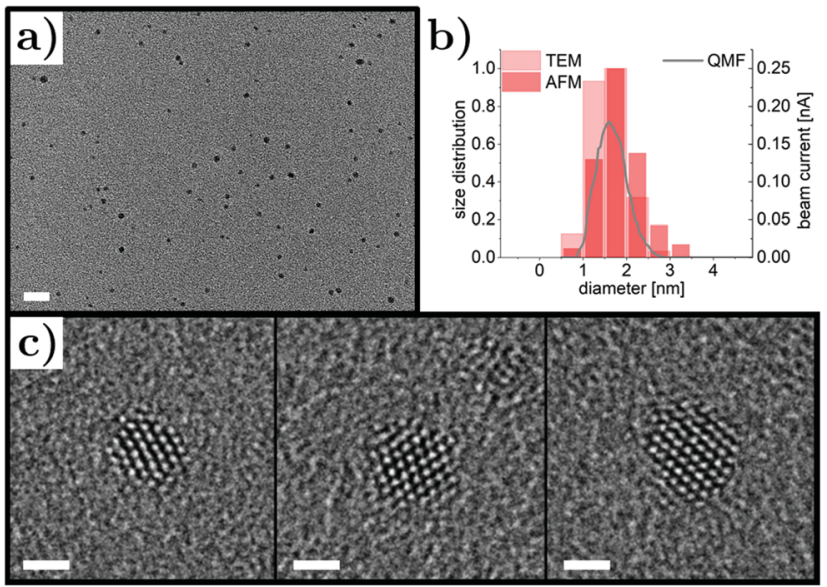

Fig. 1 (a) Low-magnification transmission electron micrograph showing well-dispersed size-selected Pt nanoparticles on a carbon support film (scale bar $10 \mathrm{~nm}$ ). (b) Nanoparticle size distributions obtained from transmission electron microscopy (TEM) and atomic force microscopy (AFM) characterization compared to the quadrupole mass filter (QMF) beam current recorded during nanoparticle deposition. (c) High-resolution transmission electron micrographs of three representative Pt nanoparticles with single-crystalline structure (scale bars $1 \mathrm{~nm}$ ).

(synthesis conditions detailed in Methods section), which can be seen in the low-magnification TEM micrograph in Fig. 1a. The nanoparticles were well-dispersed with no signatures of agglomeration and their density was determined to be around $4600 \mu \mathrm{m}^{-2}$ for $20 \mathrm{~min}$ deposition time. Size distributions obtained by TEM and AFM characterization were in good agreement and average nanoparticle sizes of $1.60 \mathrm{~nm}$ (TEM) and $1.85 \mathrm{~nm}$ (AFM) were found.

In Fig. $1 \mathrm{~b}$, the distributions are shown with the beam current signal of the QMF in the deposition system, demonstrating excellent nanoparticle size control. The crystal structure of the Pt nanoparticles was studied by aberration-corrected high-resolution TEM; three representative micrographs are presented in Fig. 1c. The nanoparticles were imaged along the (110) zone axes and the lattice spacings were consistent with the face-centered cubic structure of Pt. Although no extended facets were present due to the ultrasmall size, a tendency for faceting with (111) surfaces was observed, which could be explained in terms of Pt surface energies ${ }^{46}$ and thermodynamic equilibrium shape considerations. ${ }^{47}$ In magnetron sputtering inert-gas condensation, atoms are sputtered off the target material by a plasma process, cool down via collisions with $\mathrm{Ar}$ gas atoms and form clusters after reaching temperatures suitable for bond formation. A recent study showed that the initial cluster formation of noble metals during gas-phase synthesis can be significantly influenced by their electronic configuration. ${ }^{48}$ It is expected that the observed morphology of the Pt nanoparticles presented here is a result of comparatively slow cluster nucleation due to the high stability of dimers compared to trimers and, hence, slowed down growth kinetics, which reduces the nanoparticle yield but favors homogeneity. The latter is of significant importance due to the size and shape dependence of Pt nanoparticle catalytic activity. ${ }^{49-51}$ a)

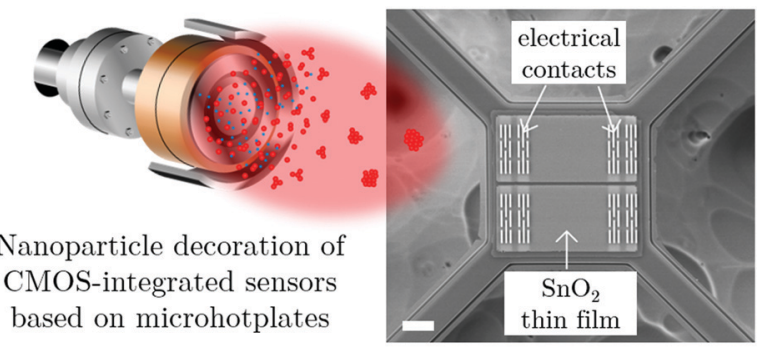

b)

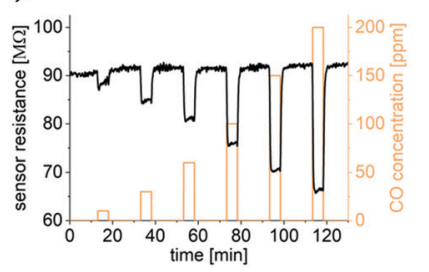

c)

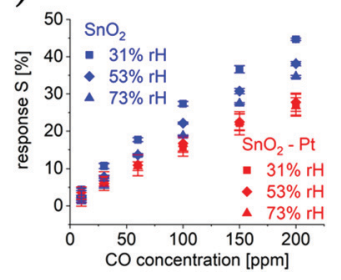

Fig. 2 (a) Schematic of magnetron sputtering inert-gas condensation source for the nanoparticle decoration of chemical sensor devices realized in complementary metal-oxide-semiconductor (CMOS) technology. The scanning electron microscopy image shows a microhotplate device suspended on four arms with $\mathrm{SnO}_{2}$ sensing layer (scale bar $10 \mu \mathrm{m}$ ). (b) Electrical resistance change of $\mathrm{SnO}_{2}$ thin film decorated with Pt nanoparticles during exposure to six pulses with increasing $\mathrm{CO}$ concentrations between 10 ppm and 200 ppm (53\% relative humidity, $400{ }^{\circ} \mathrm{C}$ operation temperature). (c) Comparison of sensor response $\mathrm{S}$ of pristine and nanoparticle-decorated $\mathrm{SnO}_{2}$ sensor device for three different relative humidity levels (400 ${ }^{\circ} \mathrm{C}$ operation temperature).

The ultrasmall size-selected Pt nanoparticles were applied for the surface functionalization of CMOS-integrated chemical sensors based on nanocrystalline $\mathrm{SnO}_{2}$ thin films. The scanning electron microscopy image in Fig. 2a shows a typical sensor device, consisting of a microhotplate $(\sim 70 \times 70 \mu \mathrm{m})$ suspended on four arms with electrical contacts connected to the underlying metallization layers and the gas-sensitive $\mathrm{SnO}_{2}$ layer on top. During the magnetron sputtering-based gas-phase synthesis process, the pre-formed Pt nanoparticles were transported directly onto the CMOS chips by means of a pressure differential between the aggregation zone and the deposition chamber, which enables nanoparticle decoration without requiring additional precursors or solvents. After passing through the QMF for size filtration, the nanoparticles are deposited onto the sample in the soft-landing regime, ${ }^{21}$ which minimizes damage to both the nanoparticles and the substrate resulting from the impact during deposition. The performance of pristine and nanoparticle-decorated devices was characterized for $\mathrm{CO}$ sensing in humid atmosphere at operation temperatures between $350{ }^{\circ} \mathrm{C}$ and $400{ }^{\circ} \mathrm{C}$, corresponding to microhotplate power consumptions between $12.3 \mathrm{~mW}$ and $13.9 \mathrm{~mW}$. Measurement results at $400{ }^{\circ} \mathrm{C}$ and $53 \%$ relative humidity are presented in Fig. $2 \mathrm{~b}$ showing an electrical resistance decrease of the $\mathrm{SnO}_{2}$-based sensor device during exposure to the reducing gas $\mathrm{CO}$, which is expected for n-type metal oxide semiconductors. ${ }^{52}$ The sensor response $\mathrm{S}$ was evaluated for pristine and nanoparticle-decorated sensors for three relative humidity levels (Fig. 2c). The sensor response $\mathrm{S}$ of 
the nanoparticle-decorated device was comparable to the pristine $\mathrm{SnO}_{2}$ device at low $\mathrm{CO}$ concentrations but showed generally lower responses at higher $\mathrm{CO}$ concentrations. The pristine sensor exhibited significant humidity interference effects with decreasing $\mathrm{CO}$ response for increased relative humidity levels, which is commonly observed for undoped $\mathrm{SnO}_{2}$ materials. ${ }^{53}$ In contrast, Pt nanoparticle decoration led to sensor responses with negligible humidity interference, demonstrating the marked impact of surface functionalization on the device performance. The influence of metal oxide doping/surface decoration on humidity interference effects in CO sensing have been comprehensively studied in previous literature. Reduced humidity interference was reported for Pd additives, ${ }^{54-57} \mathrm{NiO}$ loading, ${ }^{58} \mathrm{Sb}$ doping, ${ }^{59}$ and Pt doping; $;^{19,20,54,55}$ size-dependent effects were reported for Pd nanoparticle surface decoration. ${ }^{60}$ However, in most cases thick film-based devices and related synthesis/doping approaches have been used, which complicates a direct comparison with the presented results due to differences in sensor morphology and in the way dopants are incorporated into the sensing layer. Hence, the $\mathrm{CO}$ sensing characteristics of our $\mathrm{SnO}_{2}-\mathrm{Pt}$ nanomaterial system and its atomic-scale structure will be further discussed to gain a better understanding of the underlying solid-gas interaction and sensor transduction mechanisms.

Sensor characterization at lower operation temperatures of $350{ }^{\circ} \mathrm{C}$ and $375{ }^{\circ} \mathrm{C}$ (performed before the $400{ }^{\circ} \mathrm{C}$ measurement) showed mostly similar characteristics. However, the sensor device decorated with $\mathrm{Pt}$ nanoparticles was very reactive to $\mathrm{CO}$ in the beginning of the $350{ }^{\circ} \mathrm{C}$ measurement cycle, showing atypical gas response behavior that diminished over time. After stabilization, the sensor response at $350{ }^{\circ} \mathrm{C}$ was comparable to the case of $400{ }^{\circ} \mathrm{C}$ presented above. It is assumed that the $\mathrm{Pt}$ nanoparticles undergo changes in structure and/or chemical composition, which motivated us to further study the ultrasmall Pt nanocatalysts supported on $\mathrm{SnO}_{2}$ by means of in situ TEM.

As a first step, samples based on nanocrystalline $\mathrm{SnO}_{2}$ layers deposited on silicon nitride TEM support films were investigated. A high-resolution TEM micrograph and a selected area electron diffraction pattern is presented in Fig. 3a. The polycrystalline structure is evident with grain sizes well below the film thickness of $50 \mathrm{~nm}$, resulting in a relatively compact film. The rutile $\mathrm{SnO}_{2}$ phase with tetragonal structure was found and typical grain sizes around $4 \mathrm{~nm}$ were observed. These results are consistent with previous characterization data of the morphology, chemical composition and crystalline structure of nanocrystalline $\mathrm{SnO}_{2}$ thin films obtained by the same method. ${ }^{61,62}$ To identify ultrasmall Pt nanoparticles, bright field imaging was not suitable due to the considerably larger $\mathrm{SnO}_{2}$ film thickness and thus high-angle annular dark field imaging was employed. Nanoparticles could be seen as spots with brighter contrast (Fig. $3 \mathrm{~b}$ ) due to the large atomic number of Pt, which was confirmed by energy-dispersive X-ray spectroscopy (note that the $\mathrm{Cu} \mathrm{K} \alpha$ signal can be attributed to the sample holder). The $\mathrm{SnO}_{2}$ thin film decorated with Pt nanoparticles was in situ heated to $350{ }^{\circ} \mathrm{C}$ at an oxygen pressure of 20 mbar inside the microscope column and characterized

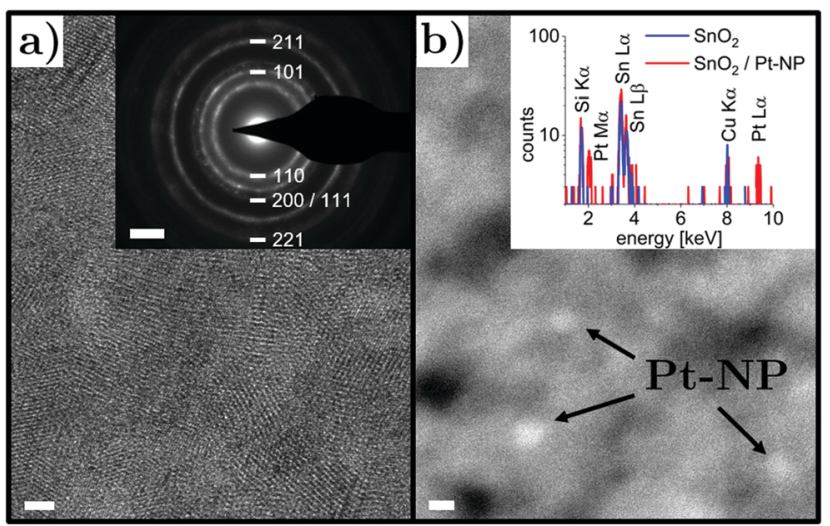

Fig. 3 (a) High-resolution transmission electron micrograph of nanocrystalline $\mathrm{SnO}_{2}$ thin film (scale bar $2 \mathrm{~nm}$ ). Inset: Selected area electron diffraction pattern consistent with polycrystalline rutile structure (scale bar $2 \mathrm{~nm}^{-1}$ ). (b) High-angle annular dark field image of nanocrystalline $\mathrm{SnO}_{2}$ layer decorated with Pt nanoparticles (scale bar $2 \mathrm{~nm}$ ). Inset: Energydispersive $\mathrm{X}$-ray spectrum of $\mathrm{SnO}_{2}$ film at positions with and without Pt nanoparticle.

again in vacuum after cooling down to room temperature. The nanocrystalline structure of the $\mathrm{SnO}_{2}$ layer did not show marked changes, which was expected due to the prior annealing process at $400{ }^{\circ} \mathrm{C}$. Pt nanoparticles were found again after the in situ heating step in an oxygen-containing environment, which indicates thermal stability of the nanoparticle morphology on the nanocrystalline $\mathrm{SnO}_{2}$ support.

However, a more detailed analysis of the atomic-scale structure of ultrasmall Pt nanoparticles after in situ experiments is hampered by the comparatively thick polycrystalline $\mathrm{SnO}_{2}$ support. Consequently, we performed additional experiments using single-crystalline $\mathrm{SnO}_{2}$ nanowires as support for the $\mathrm{Pt}$ nanoparticles, serving as model system. In particular, $\mathrm{SnO}_{2}$ nanowires were mechanically transferred to membrane-based heating chips for in situ TEM and subsequently decorated with ultrasmall Pt nanoparticles. TEM imaging was performed before and after in situ heating to $350{ }^{\circ} \mathrm{C}$ at an oxygen pressure of 20 mbar at intermediate magnification, and representative results are shown in Fig. 4. Direct comparison of micrographs taken from the same sample position shows that the Pt nanoparticles did not migrate and did not ripen significantly during the heating step. This further confirms that Pt nanoparticles are generally stable on $\mathrm{SnO}_{2}$ at $350{ }^{\circ} \mathrm{C}$, which is an important finding for the interpretation of the chemoresistive sensing results presented above. Our results are in line with previous reports on Pt nanoparticles supported on $\mathrm{SiO}_{2}{ }^{63}$ and $\mathrm{Al}_{2} \mathrm{O}_{3},{ }^{64,65}$ which demonstrated that nanoparticle sintering in oxygen-containing atmosphere occurred at $600{ }^{\circ} \mathrm{C}$ or above. The average nanoparticle size after thermal oxidation increased by $12 \%$ to $1.8 \mathrm{~nm}$, which is attributed to oxidation and morphological changes discussed in the following.

A more detailed investigation of the $\mathrm{SnO}_{2}$ nanowiresupported Pt nanoparticles using high-resolution TEM revealed further aspects of the nanoparticle structure after the in situ heating experiment (Fig. 5). Elongated morphologies related to 


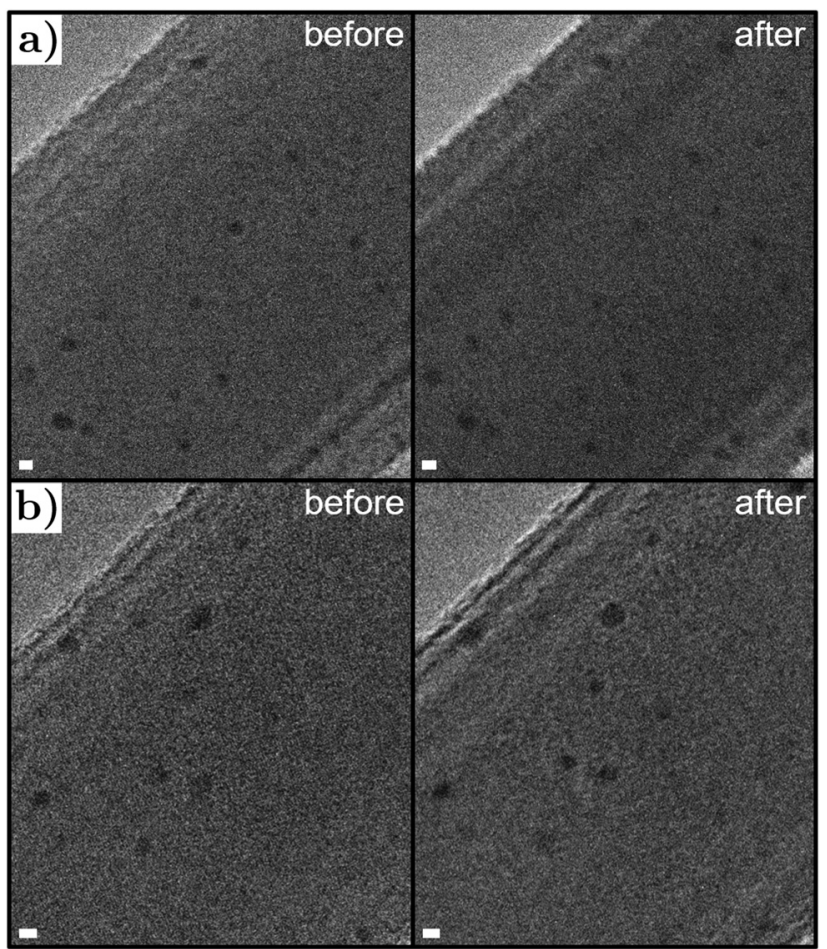

Fig. 4 Transmission electron micrographs of Pt nanoparticles supported on single-crystalline $\mathrm{SnO}_{2}$ nanowires before and after in situ heating to $350{ }^{\circ} \mathrm{C}$ at an oxygen pressure of 20 mbar for two different nanowires shown in (a) and (b), respectively. All scale bars are $2 \mathrm{~nm}$.

solid-state wetting were commonly observed and often nanoparticles with disordered crystal structure were found. It is expected that the latter is a result from oxygen incorporation into the nanoparticle lattice. In some cases crystalline planes could be identified providing further evidence for Pt nanoparticle oxidation, as the lattice spacings corresponded to Pt oxide phases rather than metallic Pt. Interestingly, the smallest clusters showed an epitaxial relationship with the $\mathrm{SnO}_{2}$ nanowire support, as can be seen in the right micrograph in Fig. 5. This observation reminds of a recent study demonstrating coherent interfaces between $\mathrm{PtO}_{2}$ nanoparticles and rutile $\mathrm{TiO}_{2}$ supports. ${ }^{66}$ Similarly, an epitaxial relationship between $\mathrm{CuO}$ nanowire supports and Pd nanoparticles after thermal oxidation has been identified, resulting from an interface-driven

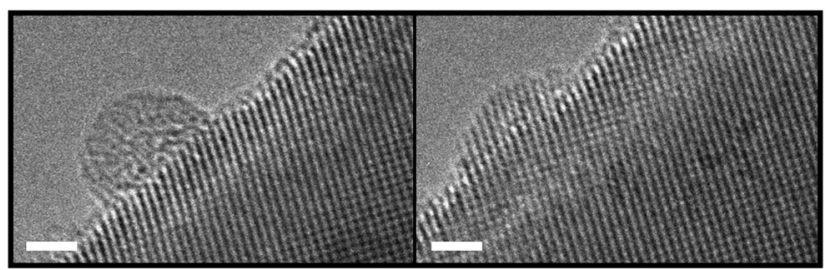

Fig. 5 High-resolution transmission electron micrographs of Pt nanoparticles supported on $\mathrm{SnO}_{2}$ nanowire after in situ heating to $350{ }^{\circ} \mathrm{C}$ at an oxygen pressure of 20 mbar (scale bars $2 \mathrm{~nm}$ ), resulting in nanoparticles with disordered structure (left) and clusters with crystalline structure aligned with respect to the nanowire support (right). oxidation mechanism. ${ }^{67}$ PdO nanoparticles epitaxially aligned to $\mathrm{MgO}$ substrates have also been found, but their formation was explained by $\mathrm{PdO}$ nanoparticle nucleation and growth enabled by Pd surface diffusion. ${ }^{68,69}$ Furthermore, epitaxial relationships between nanoparticle and support have been observed for metallic $\mathrm{Au}^{70,71}$ or $\mathrm{Rh}^{72}$ catalysts after treatment at elevated temperatures. In addition to size- and shapedependent effects, ${ }^{51,73}$ such strong nanoparticle-support interactions play an important role for nanocatalyst reactivity and thermal stability. ${ }^{66,74}$

The question arises which Pt oxide phase was formed on the $\mathrm{SnO}_{2}$ support and how this would influence the chemoresistive sensing properties of the $\mathrm{SnO}_{2}-\mathrm{Pt}$ devices presented above. The nanoparticle lattice spacings observed in our high-resolution TEM analysis were in good agreement with $\mathrm{Pt}_{3} \mathrm{O}_{4}$ and $\beta-\mathrm{PtO}_{2}$ phases. The authors of Nur et al. ${ }^{66}$ have argued that, despite the similar crystal structures of their rutile $\mathrm{TiO}_{2}$ support and $\beta-\mathrm{PtO}_{2}$, the occurrence of the latter is not expected as the synthesis of this phase typically requires high temperatures and pressures. Further, $\mathrm{Pt}_{3} \mathrm{O}_{4}$ was formed during the oxidation of $\mathrm{Pt}$ nanoparticles supported on $\mathrm{MgO}^{75}$ and on carbon, ${ }^{76}$ whereas no $\beta-\mathrm{PtO}_{2}$ was identified. We consequently infer that the Pt nanoparticle functionalization of $\mathrm{SnO}_{2}$ thin films for chemical sensing at elevated temperatures in oxygen atmosphere can most likely be explained by the presence of disordered Pt oxide and $\mathrm{Pt}_{3} \mathrm{O}_{4}$ clusters. The observed pronounced oxidation of ultrasmall $\mathrm{Pt}$ nanoparticles supported on $\mathrm{SnO}_{2}$ is consistent with X-ray photoelectron spectroscopy studies in literature for clusters in a comparable size range on different substrates. ${ }^{73,76}$ Note that the presented TEM analysis cannot exclude the possibility of Sn doping of the Pt nanoparticles, but this case is not expected to lead to significant changes in $\mathrm{CO}$ reactivity. $^{77}$

The sensing mechanism of $\mathrm{SnO}_{2}$-based devices in oxygencontaining atmosphere has been explained by oxygen species adsorbed on the $\mathrm{SnO}_{2}$ surface, acting as electron acceptor levels that affect electrical conductivity. ${ }^{78,79}$ The influence of water vapor has been ascribed to the adsorption of molecular as well as surface hydroxil groups. ${ }^{80}$ It is expected that the sensing mechanism for the nanocrystalline $\mathrm{SnO}_{2}$ thin film devices presented here is governed by the space charge regions at grain surfaces and interfaces. The CO sensor signal can be attributed to $\mathrm{CO}$ reacting with ionosorbed oxygen or direct reactions at the $\mathrm{SnO}_{2}$ surface. ${ }^{79}$ Humidity interference effects can be understood by a competition between $\mathrm{CO}$ and water vapor for reaction sites. In our $\mathrm{SnO}_{2}-\mathrm{Pt}$ nanomaterial system, we observed minimized humidity interference effects in CO sensing resulting from surface decoration with ultrasmall Pt nanoparticles. Correlating the presented TEM characterization with the sensing measurements, it can be assumed that the observed nanoparticle-support interactions play a central role for the $\mathrm{CO}$ sensing mechanism in humid atmosphere. The emergence of oxidized Pt clusters with crystalline structure aligned with respect to the support leads to distinct interfaces and reaction sites, most likely affecting the chemical reactivity. In previous literature, the importance of the three-phase boundary 
of Pt oxide, $\mathrm{SnO}_{2}$ and the gas phase for $\mathrm{CO}$ sensing in humid atmosphere has been highlighted. ${ }^{20}$ We expect similarities in our case with oxidized ultrasmall Pt clusters influencing the $\mathrm{SnO}_{2}$ layer mainly by chemical sensitization. Minimized humidity interference effects could be attributed to $\mathrm{CO}$ reactions at interfacial sites that cause the sensor signal. Moreover, the lowered sensor response of $\mathrm{SnO}_{2}-\mathrm{Pt}$ devices at higher $\mathrm{CO}$ concentrations could be attributed to direct $\mathrm{CO}$ oxidation on oxidized Pt clusters without electronic coupling to the sensing layer. ${ }^{20,81}$ Such a chemical sensitization scenario would be supported by the high catalytic $\mathrm{CO}$ oxidation activity of $\mathrm{Pt}_{3} \mathrm{O}_{4}{ }^{82}$ and by the high reactivity of ultrasmall nanoparticles in general due to a large number of undercoordinated surface sites. ${ }^{83,84}$ Building on the results presented here, interesting questions and opportunities for future studies emerge, e.g., in situ TEM experiments at higher pressure of the reactive gas atmosphere, morphology and oxidation state changes of ultrasmall Pt nanoparticles induced by exposure to water vapor and $\mathrm{CO},{ }^{85}$ or the effect of Pt nanoparticle size/shape on humidity interference effects and the overall chemical sensing performance.

\section{Conclusions}

We have presented the fabrication of size-selected crystalline Pt nanoparticles with an average diameter below $2 \mathrm{~nm}$ by magnetron sputtering inert-gas condensation, a solvent-free gas-phase synthesis method for seamless nanoparticle integration with CMOS technology and chemoresistive sensor devices. Minimized humidity interference was observed in the CO sensor response of nanocrystalline $\mathrm{SnO}_{2}$ thin films decorated with Pt nanoparticles and the relevant sensing mechanisms were discussed. In situ heating experiments conducted inside an electron microscope in oxygen atmosphere at conditions relevant for sensor operation showed that the ultrasmall Pt nanoparticles did not migrate or ripen significantly. However, nanoparticle oxidation resulted in structures with pronounced crystal lattice disorder as well as clusters with epitaxial alignment to a crystalline $\mathrm{SnO}_{2}$ support. Our findings show nanoparticle-support interactions in the $\mathrm{SnO}_{2}-\mathrm{Pt}$ system and provide new insights into the stability of ultrasmall Pt nanoparticles at elevated temperatures in an oxygen environment, which is of significant importance in chemical sensing and catalysis applications.

\section{Conflicts of interest}

There are no conflicts to declare.

\section{Acknowledgements}

This work was supported by funding from the OIST Graduate University and has been partly performed within the project "MSP - Multi Sensor Platform for Smart Building Management” (FP7-ICT-2013-10 Collaborative Project, No. 611887).

\section{References}

1 J. Zhang, X. Liu, G. Neri and N. Pinna, Adv. Mater., 2016, 28, 795-831.

2 G. Korotcenkov and B. Cho, Sens. Actuators, B, 2017, 244, 182-210.

3 D. R. Miller, S. A. Akbar and P. A. Morris, Sens. Actuators, B, 2014, 204, 250-272.

4 X. Xue, L. Xing, Y. Chen, S. Shi, Y. Wang and T. Wang, J. Phys. Chem. C, 2008, 112, 12157-12160.

5 S. Park, S. An, Y. Mun and C. Lee, ACS Appl. Mater. Interfaces, 2013, 5, 4285-4292.

6 O. Lupan, T. Braniste, M. Deng, L. Ghimpu, I. Paulowicz, Y. K. Mishra, L. Kienle, R. Adelung and I. Tiginyanu, Sens. Actuators, B, 2015, 221, 544-555.

7 O. Lupan, N. Wolff, V. Postica, T. Braniste, I. Paulowicz, V. Hrkac, Y. K. Mishra, I. Tiginyanu, L. Kienle and R. Adelung, Ceram. Int., 2018, 44, 4859-4867.

8 J. Guo, J. Zhang, H. Gong, D. Ju and B. Cao, Sens. Actuators, $B, 2016,226,266-272$.

9 G. Tofighi, D. Degler, B. Junker, S. Müller, H. Lichtenberg, W. Wang, U. Weimar, N. Barsan and J.-D. Grunwaldt, Sens. Actuators, B, 2019, 292, 48-56.

10 Y.-H. Lin, Y.-C. Hsueh, P.-S. Lee, C.-C. Wang, J. M. Wu, T.-P. Perng and H. C. Shih, J. Mater. Chem., 2011, 21, 10552-10558.

11 G.-J. Sun, S.-W. Choi, S.-H. Jung, A. Katoch and S. S. Kim, Nanotechnology, 2012, 24, 025504.

12 J. Shin, S.-J. Choi, I. Lee, D.-Y. Youn, C. O. Park, J.-H. Lee, H. L. Tuller and I.-D. Kim, Adv. Funct. Mater., 2013, 23, 2357-2367.

13 X. Liu, N. Chen, B. Han, X. Xiao, G. Chen, I. Djerdj and Y. Wang, Nanoscale, 2015, 7, 14872-14880.

14 X.-T. Yin, W.-D. Zhou, J. Li, Q. Wang, F.-Y. Wu, D. Dastan, D. Wang, H. Garmestani, X.-M. Wang and Ş. Ţălu, J. Alloys Compd., 2019, 805, 229-236.

15 M. Dou, M. Hou, D. Liang, W. Lu, Z. Shao and B. Yi, Electrochim. Acta, 2013, 92, 468-473.

16 C. Marichy, G. Ercolano, G. Caputo, M. G. Willinger, D. Jones, J. Rozière, N. Pinna and S. Cavaliere, J. Mater. Chem. A, 2016, 4, 969-975.

17 J. Bae, J. Kim, H. Jeong and H. Lee, Catal. Sci. Technol., 2018, 8, 782-789.

18 A. Rabis, T. Binninger, E. Fabbri and T. J. Schmidt, J. Phys. Chem. C, 2018, 122, 4739-4746.

19 K. Großmann, S. Wicker, U. Weimar and N. Barsan, Phys. Chem. Chem. Phys., 2013, 15, 19151-19158.

20 D. Degler, H. W. Pereira de Carvalho, K. Kvashnina, J.-D. Grunwaldt, U. Weimar and N. Barsan, RSC Adv., 2016, 6, 28149-28155.

21 G. E. Johnson, R. Colby and J. Laskin, Nanoscale, 2015, 7, 3491-3503.

22 P. Grammatikopoulos, S. Steinhauer, J. Vernieres, V. Singh and M. Sowwan, Adv. Phys. X, 2016, 1, 81-100.

23 Y. Huttel, Gas-Phase Synthesis of Nanoparticles, Wiley, 2017.

24 M. K. Kennedy, F. E. Kruis, H. Fissan, B. R. Mehta, S. Stappert and G. Dumpich, J. Appl. Phys., 2003, 93, 551-560. 
25 T. Toccoli, S. Capone, L. Guerini, M. Anderle, A. Boschetti, E. Iacob, V. Micheli, P. Siciliano and S. Iannotta, IEEE Sens. J., 2003, 3, 199-205.

26 T. Mazza, E. Barborini, I. N. Kholmanov, P. Piseri, G. Bongiorno, S. Vinati, P. Milani, C. Ducati, D. Cattaneo, A. Li Bassi, C. E. Bottani, A. M. Taurino and P. Siciliano, Appl. Phys. Lett., 2005, 87, 103108.

27 M. Kennedy, F. Kruis, H. Fissan, H. Nienhaus, A. Lorke and T. Metzger, Sens. Actuators, B, 2005, 108, 62-69.

28 A. Lassesson, M. Schulze, J. van Lith and S. A. Brown, Nanotechnology, 2007, 19, 015502.

29 M. Khanuja, S. Kala, B. R. Mehta and F. E. Kruis, Nanotechnology, 2008, 20, 015502.

30 J. Vernieres, S. Steinhauer, J. Zhao, A. Chapelle, P. Menini, N. Dufour, R. E. Diaz, K. Nordlund, F. Djurabekova, P. Grammatikopoulos and M. Sowwan, Adv. Funct. Mater., 2017, 27, 1605328.

31 S. Steinhauer, V. Singh, C. Cassidy, C. Gspan, W. Grogger, M. Sowwan and A. Köck, Nanotechnology, 2015, 26, 175502.

32 S. Steinhauer, J. Vernieres, J. Krainer, A. Köck, P. Grammatikopoulos and M. Sowwan, Nanoscale, 2017, 9, 7380-7384.

33 A. Porkovich, Z. Ziadi, P. Kumar, J. Kioseoglou, N. Jian, L. Weng, S. Steinhauer, J. Vernieres, P. Grammatikopoulos and M. Sowwan, ACS Nano, 2019, 13, 12425-12437.

34 S. Vajda and M. G. White, ACS Catal., 2015, 5, 7152-7176.

35 J. Wang, H.-B. Sun, H.-Y. Pan, Y.-Y. Ding, J.-G. Wan, G.-H. Wang and M. Han, Sens. Actuators, B, 2016, 230, 690-696.

36 A. Halder, L. A. Curtiss, A. Fortunelli and S. Vajda, J. Chem. Phys., 2018, 148, 110901.

37 A. Datta, A. J. Porkovich, P. Kumar, G. Nikoulis, J. Kioseoglou, T. Sasaki, S. Steinhauer, P. Grammatikopoulos and M. Sowwan, J. Phys. Chem. C, 2019, 123, 26124-26135.

38 S. DAddato, L. Gragnaniello, S. Valeri, A. Rota, A. di Bona, F. Spizzo, T. Panozaqi and S. F. Schifano, J. Appl. Phys., 2010, 107, 104318.

39 M. Bohra, P. Grammatikopoulos, V. Singh, J. Zhao, E. Toulkeridou, S. Steinhauer, J. Kioseoglou, J.-F. Bobo, K. Nordlund, F. Djurabekova and M. Sowwan, Phys. Rev. Mater., 2017, 1, 066001.

40 L. Xing, G. H. ten Brink, B. J. Kooi and G. Palasantzas, J. Appl. Phys., 2017, 121, 024305.

41 M. Haro, V. Singh, S. Steinhauer, E. Toulkeridou, P. Grammatikopoulos and M. Sowwan, Adv. Sci., 2017, 4, 1700180.

42 S. Kumar, T. Pavloudis, V. Singh, H. Nguyen, S. Steinhauer, C. Pursell, B. Clemens, J. Kioseoglou, P. Grammatikopoulos and M. Sowwan, Adv. Energy Mater., 2018, 8, 1701326.

43 E. Brunet, T. Maier, G. Mutinati, S. Steinhauer, A. Köck, C. Gspan and W. Grogger, Sens. Actuators, B, 2012, 165, 110-118.

44 M. Siegele, C. Gamauf, A. Nemecek, G. C. Mutinati, S. Steinhauer, A. Köck, J. Kraft, J. Siegert and F. Schrank, 2013 IEEE 11th International New Circuits and Systems Conference (NEWCAS), 2013, pp. 1-4.
45 R. Wimmer-Teubenbacher, S. Steinhauer, O. von Sicard, E. Magori, J. Siegert, K. Rohracher, C. Gspan, W. Grogger and A. Köck, Mater. Today: Proc., 2015, 2, 4295-4301.

46 L. Vitos, A. Ruban, H. Skriver and J. Kollár, Surf. Sci., 1998, 411, 186-202.

47 L. D. Marks and L. Peng, J. Phys.: Condens. Matter, 2016, 28, 053001.

48 J.-G. Mattei, P. Grammatikopoulos, J. Zhao, V. Singh, J. Vernieres, S. Steinhauer, A. Porkovich, E. Danielson, K. Nordlund, F. Djurabekova and M. Sowwan, Chem. Mater., 2019, 31, 2151-2163.

49 S. Mostafa, F. Behafarid, J. R. Croy, L. K. Ono, L. Li, J. C. Yang, A. I. Frenkel and B. R. Cuenya, J. Am. Chem. Soc., 2010, 132, 15714-15719.

50 Y. Watanabe, X. Wu, H. Hirata and N. Isomura, Catal. Sci. Technol., 2011, 1, 1490-1495.

51 B. R. Cuenya and F. Behafarid, Surf. Sci. Rep., 2015, 70, 135-187.

52 N. Barsan and U. Weimar, J. Electroceram., 2001, 7, 143-167. 53 S. Wicker, M. Guiltat, U. Weimar, A. Hémeryck and N. Barsan, J. Phys. Chem. C, 2017, 121, 25064-25073.

54 G. Mandayo, E. Castaño, F. Gracia, A. Cirera, A. Cornet and J. Morante, Sens. Actuators, B, 2003, 95, 90-96.

55 P. Ménini, F. Parret, M. Guerrero, K. Soulantica, L. Erades, A. Maisonnat and B. Chaudret, Sens. Actuators, B, 2004, 103, 111-114.

56 N. Ma, K. Suematsu, M. Yuasa, T. Kida and K. Shimanoe, ACS Appl. Mater. Interfaces, 2015, 7, 5863-5869.

57 D. Koziej, N. Barsan, K. Shimanoe, N. Yamazoe, J. Szuber and U. Weimar, Sens. Actuators, B, 2006, 118, 98-104.

58 H.-R. Kim, A. Haensch, I.-D. Kim, N. Barsan, U. Weimar and J.-H. Lee, Adv. Funct. Mater., 2011, 21, 4456-4463.

59 K. Suematsu, M. Sasaki, N. Ma, M. Yuasa and K. Shimanoe, ACS Sens., 2016, 1, 913-920.

60 N. Ma, K. Suematsu, M. Yuasa and K. Shimanoe, ACS Appl. Mater. Interfaces, 2015, 7, 15618-15625.

61 A. Tischner, T. Maier, C. Stepper and A. Köck, Sens. Actuators, B, 2008, 134, 796-802.

62 E. Brunet, PhD thesis, TU Wien, 2014.

63 S. B. Simonsen, I. Chorkendorff, S. Dahl, M. Skoglundh, J. Sehested and S. Helveg, J. Catal., 2011, 281, 147-155.

64 S. B. Simonsen, I. Chorkendorff, S. Dahl, M. Skoglundh, J. Sehested and S. Helveg, J. Am. Chem. Soc., 2010, 132, 7968-7975.

65 S. B. Simonsen, I. Chorkendorff, S. Dahl, M. Skoglundh, K. Meinander, T. N. Jensen, J. V. Lauritsen and S. Helveg, J. Phys. Chem. C, 2012, 116, 5646-5653.

66 A. S. M. Nur, E. Funada, S. Kiritoshi, A. Matsumoto, R. Kakei, S. Hinokuma, H. Yoshida and M. Machida, J. Phys. Chem. C, 2018, 122, 662-669.

67 S. Steinhauer, J. Zhao, V. Singh, T. Pavloudis, J. Kioseoglou, K. Nordlund, F. Djurabekova, P. Grammatikopoulos and M. Sowwan, Chem. Mater., 2017, 29, 6153-6160.

68 N. Kasper, A. Stierle, P. Nolte, Y. Jin-Phillipp, T. Wagner, D. de Oteyza and H. Dosch, Surf. Sci., 2006, 600, 2860-2867. 
69 P. Nolte, A. Stierle, N. Kasper, N. Y. Jin-Phillipp, H. Reichert, A. Rühm, J. Okasinski, H. Dosch and S. Schöder, Phys. Rev. B: Condens. Matter Mater. Phys., 2008, 77, 115444.

70 T. Akita, M. Okumura, K. Tanaka, M. Kohyama and M. Haruta, J. Mater. Sci., 2005, 40, 3101-3106.

71 J. González, J. Hernández, M. López-Haro, E. del Río, J. Delgado, A. Hungría, S. Trasobares, S. Bernal, P. Midgley and J. Calvino, Angew. Chem., Int. Ed., 2009, 48, 5313-5315.

72 S. Bernal, F. Botana, J. Calvino, G. Cifredo, J. Pérez-Omil and J. Pintado, Catal. Today, 1995, 23, 219-250.

73 L. K. Ono, J. R. Croy, H. Heinrich and B. Roldan Cuenya, J. Phys. Chem. C, 2011, 115, 16856-16866.

74 L. K. Ono, B. Yuan, H. Heinrich and B. R. Cuenya, J. Phys. Chem. C, 2010, 114, 22119-22133.

75 U. Hejral, A. Vlad, P. Nolte and A. Stierle, J. Phys. Chem. C, 2013, 117, 19955-19966.

76 R. Banerjee, D. A. Chen, S. Karakalos, M.-L. C. Piedboeuf, N. Job and J. R. Regalbuto, ACS Appl. Nano Mater., 2018, 1, 5876-5884.
77 P. Ferrari, L. M. Molina, V. E. Kaydashev, J. A. Alonso, P. Lievens and E. Janssens, Angew. Chem., Int. Ed., 2016, 55, 11059-11063.

78 S. Lenaerts, J. Roggen and G. Maes, Spectrochim. Acta, Part A, 1995, 51, 883-894.

79 N. Barsan, J. Rebholz and U. Weimar, Sens. Actuators, B, 2015, 207, 455-459.

80 N. Yamazoe, J. Fuchigami, M. Kishikawa and T. Seiyama, Surf. Sci., 1979, 86, 335-344.

81 P. Kutukov, M. Rumyantseva, V. Krivetskiy, D. Filatova, M. Batuk, J. Hadermann, N. Khmelevsky, A. Aksenenko and A. Gaskov, Nanomaterials, 2018, 8, 917.

82 N. Seriani, W. Pompe and L. C. Ciacchi, J. Phys. Chem. B, 2006, 110, 14860-14869.

83 E. Altman and R. Gorte, Surf. Sci., 1988, 195, 392-402.

84 B. Hammer, O. Nielsen and J. Nørskov, Catal. Lett., 1997, 46, 31-35.

85 H. Yoshida, H. Omote and S. Takeda, Nanoscale, 2014, 6, 13113-13118. 